\title{
Efek Penggunaan Leg Wrapping terhadap Kejadian Hipotensi Selama Anestesi Spinal pada Pasien Seksio Sesarea
}

\author{
Yunita Susanto Putri, ${ }^{1}$ Iwan Fuadi, ${ }^{2}$ Tatang Bisri ${ }^{2}$ \\ ${ }^{1}$ Rumah Sakit Santosa Kopo, ${ }^{2}$ Departemen Anestesiologi dan Terapi Intensif \\ Fakultas Kedokteran Universitas Padjadjaran/Rumah Sakit Dr. Hasan Sadikin Bandung
}

\begin{abstract}
Abstrak
Hipotensi merupakan komplikasi tersering selama anestesi spinal dengan insidensi $>80 \%$ meskipun telah diberikan cairan preloading, posisi ibu left lateral tilt, dan penggunaan vasopresor. Terdapat teknik lain untuk mencegah terjadi hipotensi, yaitu penggunaan leg wrapping yang dapat memperbaiki aliran balik vena dengan meningkatkan volume darah sentral. Penelitian ini bertujuan menilai efek penggunaan leg wrapping terhadap kejadian hipotensi selama anestesi spinal pada pasien seksio sesarea. Penelitian bersifat eksperimental acak terkontrol buta tunggal dengan randomisasi secara acak sederhana yang melibatkan 40 ibu hamil American Society of Anesthesiologists (ASA) II yang menjalani seksio sesarea dengan anestesi spinal di Central Operating Theatre (COT) lantai 3, Rumah Sakit Dr. Hasan Sadikin Bandung pada bulan Juni-Juli 2015. Subjek penelitian dikelompokkan menjadi dua, yaitu 20 subjek dengan leg wrapping dan 20 subjek tanpa leg wrapping. Tekanan darah dan laju nadi diperiksa setiap dua menit sampai bayi lahir. Data dianalisis dengan uji-t tidak berpasangan dan chi-kuadrat, nilai $\mathrm{p}<0,05$ dianggap bermakna. Analisis statistik menunjukkan kejadian hipotensi pada kelompok tanpa leg wrapping 95\% (19 orang) dan 0\% pada kelompok dengan leg wrapping dengan perbedaan bermakna $(\mathrm{p}<0,05)$. Secara keseluruhan, hemodinamik kelompok dengan leg wrapping lebih stabil dibanding dengan kelompok tanpa leg wrapping. Simpulan, penggunaan leg wrapping sebelum dilakukan anestesi spinal pada pasien yang menjalani seksio sesarea menurunkan angka kejadian hipotensi.
\end{abstract}

Kata kunci: Anestesi spinal, hipotensi, leg wrapping, seksio sesarea

\section{Effect of Leg Wrapping on Hypotension Incidence in Cesarean Section with Spinal Anesthesia}

\begin{abstract}
Hypotension is the most common complication of spinal anesthesia. The incidence remains high despite adequate fluid preloading, left lateral tilt positioning, and vasopressors use. There is a technique that can be used to prevent hypotension, which is referred as leg wrapping. Leg wrapping can improve venous return by increasing central blood volume. This study aimed to compare the hypotension incidence between with and without leg wrapping during spinal anesthesia for caesarean section. The method used was single blind randomized controlled trial with simple randomization, involving 40 pregnant women ASA II, who underwent cesarean section with spinal anesthesia in COT 3rd floor Dr. Hasan Sadikin General Hospital Bandung during the period of June-July 2015. Subjects were grouped into with leg wrapping and without leg wrapping groups with 20 subjects in each group. Blood pressure and heart rate were recorded every two minutes until the baby was born. Data were then analyzed using t-test and chi-square test with $p$ values $<0.05$ considered significant. The statistical analysis showed that there were significant differences in the incidence of hypotension $(\mathrm{p}<0.05)$ in the group without leg wrapping, i.e. 95\% (19 people), and the group with leg wrapping, i.e. $0 \%$. Overall, hemodynamics of the leg wrapping group was more stable than the group without leg wrapping. In conclusion, leg wrapping prior to spinal anesthesia in patients undergoing cesarean section will reduce incidence of hypotension.
\end{abstract}

Key words: Cesarean section, hypotension, leg wrapping, spinal anesthesia

Korespondensi: Yunita Susanto Putri, dr., SpAn, Rumah Sakit Santosa Kopo, Jl. Raya Kopo No.413, Kb. Lega, Bojongloa Kidul, Tlpn. 022-54280333, Mobile 081394505945, Email yunitasputri@yahoo.com 


\section{Pendahuluan}

Seksio sesarea merupakan operasi yang sering dilakukan dengan jumlah semakin meningkat setiap tahunnya, hingga saat ini persalinan dengan seksio sesarea mencapai angka 15\%$30 \%$ dari seluruh persalinan. Teknik anestesi pada seksio sesarea dapat dilakukan dengan anestesi umum maupun anestesi regional. ${ }^{1,2}$

Anestesi regional merupakan teknik pilihan dibanding dengan anestesi umum karena anestesi umum memberikan risiko morbiditas dan mortalitas ibu yang lebih besar. Kematian karena anestesi umum berhubungan dengan masalah jalan napas, seperti ketidakmampuan intubasi, ketidakmampuan ventilasi ataupun aspirasi pneumonia, sedangkan kematian karena anestesi regional berhubungan dengan penyebaran blokade dermatom yang luas dan toksisitas obat anestesi lokal. Keuntungan lain anestesi regional adalah paparan obat depresan pada bayi minimal, risiko aspirasi pneumonia lebih kecil, ibu tetap bangun pada saat bayi dilahirkan, dan penggunaan opioid lebih sedikit. ${ }^{1,2}$

Teknik anestesi regional pada seksio sesarea dapat dilakukan dengan menggunakan teknik anestesi neuraksial yang meliputi anestesi regional spinal, epidural, ataupun kombinasi spinal-epidural. Anestesi spinal merupakan teknik yang sederhana dan dapat diandalkan, mempunyai onset blokade simpatis yang cepat dan sempurna. Hanya dibutuhkan sejumlah kecil obat anestesi lokal untuk menghasilkan blokade spinal fungsional sehingga risiko ibu untuk mengalami toksisitas anestesi lokal sistemik dapat diabaikan. Keunggulan teknik anestesi spinal menjadikannya teknik anestesi yang paling umum dilakukan untuk persalinan dengan seksio sesarea. ${ }^{3}$

Hipotensi merupakan komplikasi tersering selama anestesi spinal dengan insidensi yang mencapai lebih dari 80\%. Angka kejadian hipotensi tersebut tetap tinggi meskipun telah diberikan cairan preloading, posisi ibu left lateral tilt, dan penggunaan vasopresor. ${ }^{4}$

Banyak metode/cara yang dapat digunakan untuk mencegah/meminimalisasi terjadinya hipotensi, akan tetapi sampai saat ini belum ada teknik yang ideal. Metode tersebut dapat dilakukan baik secara farmakologis ataupun nonfarmakologis. Metode yang paling banyak digunakan adalah profilaksis preloading cairan dengan kristaloid ataupun koloid (pemberian cairan intravena sebanyak 1 sampai $2 \mathrm{~mL} /$ kgBB sebelum dilakukan tindakan anestesi spinal), left uterine displacement, penggunaan vasopresor seperti efedrin atau fenilefrin, dan intervensi mekanik untuk meningkatkan volume darah sentral. Beberapa cara untuk meningkatkan volume darah sentral, antara lain adalah metode fisik seperti penggunaan leg wrapping, inflatable splints/boots, atau stoking antitromboemboli. Metode tersebut cukup efektif untuk mencegah hipotensi. ${ }^{1,5,6}$

Penelitian penggunaan leg wrapping sudah dilakukan di beberapa tempat dan penelitian terakhir dilakukan pada tahun 2014 di India dengan hasil yang serupa dengan penelitian sebelumnya, yaitu angka kejadian hipotensi hanya $10 \%$ dari pasien yang dilakukan leg wrapping sebelum anestesi spinal, sedangkan pada pasien yang tidak dilakukan leg wrapping hipotensi terjadi pada $33,33 \%$ pasien. ${ }^{1}$ Penelitian ini bertujuan untuk menilai efek penggunaan leg wrapping terhadap kejadian hipotensi selama anestesi spinal pada pasien seksio sesarea.

\section{Subjek dan Metode}

Penelitian ini adalah penelitian eksperimental dengan memakai uji klinik buta tunggal yang dilakukan setelah mendapat persetujuan dari Komite Etik Penelitian Kesehatan Fakultas Kedokteran Universitas Padjadjaran/Rumah Sakit Dr. Hasan Sadikin Bandung. Penelitian dilakukan pada bulan Juni-Juli 2015 di Central Operating Theatre (COT) Rumah Sakit Dr. Hasan Sadikin Bandung. Subjek penelitian adalah wanita hamil yang menjalani seksio sesarea elektif atau segera dengan anestesi spinal. Kriteria inklusi adalah hamil aterm, status fisik American Society of Anesthesiologists (ASA) II, usia 18-35 tahun, dan tinggi badan di atas $145 \mathrm{~cm}$. Kriteria eksklusi adalah kehamilan gemeli, polihidramnion, dan pasien menderita hipotensi dengan tekanan darah sistol (TDS) 
$<90$ mmHg. Sampel akan dikeluarkan apabila terjadi kegagalan pada anestesi spinal setelah ditunggu 15 menit atau ketinggian blok di atas dermatom torakal 4.

Penentuan besar sampel digunakan rumus uji analisis komparatif tidak berpasangan, dengan tingkat kepercayaan $(\alpha)$ 95\% dan besar uji kekuatan $80 \%$. Besar sampel minimal yang dibutuhkan minimal 20 subjek untuk setiap kelompok. Sampel ditentukan menggunakan metode acak sederhana yang dibagi menjadi dua kelompok dan setiap kelompok terdiri atas 20 pasien. Kelompok I tidak dilakukan leg wrapping sebelum anestesi spinal dan kelompok II dilakukan leg wrapping sebelum anestesi spinal. Leg wrapping menggunakan perban elastik (tensocrepe ${ }^{\circledR}$ ) dilakukan dari mulai pergelangan kaki sampai ketinggian setengah paha, adapun parameter kekuatan pembalutan diukur secara subjektif dengan menilai kenyamanan pasien dan secara objektif dengan menilai capillary refill time kurang dari dua detik dan penilaian saturasi oksigen pada jari kaki pasien tidak berubah sebelum dengan setelah leg wrapping (Gambar 1).

Setiap pasien akan dilakukan pemasangan elektrokardiografi (EKG), alat pantau tekanan darah noninvasif, dan juga pulse oksimetri. Setelah diukur tekanan darah sistol, diastol, laju nadi, dan saturasi oksigen, diberi cairan preloading dengan cairan Ringer laktat (RL) $20 \mathrm{~mL} / \mathrm{kgBB}$ selama 20 menit. Setelah pasien didudukkan, dilakukan tindakan aseptik dan antiseptik di sekitar daerah penyuntikan, lalu dilakukananestesi spinal dengan jarum standar 25G pada celah vertebra lumbal 3-4 atau 4-5, maksimal penusukan tiga kali. Setelah keluar cairan serebrospinal, disuntikkan campuran $10 \mathrm{mg}$ bupivakain heavy $0,5 \%$ dengan fentanil $25 \mu \mathrm{g}$ dengan kecepatan $1 \mathrm{~mL} / 5$ detik yang akan dihitung menggunakan stopwatch. Waktu selesainya penyuntikan dipakai sebagai awal perhitungan waktu, selanjutnya pasien segera dibaringkan dalam posisi telentang horizontal, lalu kepala diberi bantal dan oksigen 2 liter per menit melalui nasal.

Efektivitas blokade sensorik dinilai dengan tes pinprick, diharapkan ketinggian blok Th5Th7 tercapai. Tekanan darah sistol, diastol, tekanan arteri rata-rata, dan laju nadi diukur setiap dua menit sampai bayi lahir. Selama pembedahan, kejadian hipotensi, bradikardia, mual, muntah, menggigil, dan efek samping lain dicatat. Apabila terjadi hipotensi, yaitu penurunan tekanan darah sistol $>20 \%$ dari tekanan darah sistol awal, diberikan bolus efedrin $5 \mathrm{mg}$ intravena. Sulfas atropin $0,5 \mathrm{mg}$ intravena diberikan apabila terjadi bradikardia (laju nadi $<45 \mathrm{x} /$ menit). Dilakukan pencatatan jumlah penggunaan efedrin dan sulfas atropin selama operasi.

Analisis statistik data hasil penelitian dalam bentuk data numerik memakai uji-t apabila data berdistribusi normal, sedangkan jika data

Tabel 1 Karakteristik Umum Subjek Penelitian pada Kedua Kelompok

\begin{tabular}{lccc}
\hline \multicolumn{1}{c}{ Karakteristik Umum } & $\begin{array}{c}\text { Kelompok } \\
\text { Tanpa Wrapping } \\
(\mathbf{n = 2 0 )}\end{array}$ & $\begin{array}{c}\text { Kelompok } \\
\text { Wrapping } \\
(\mathbf{n = 2 0}\end{array}$ & Nilai p \\
\hline Usia (tahun) & $27,6(6,2)$ & $27,3(7,7)$ & $0,911^{\text {b) }}$ \\
Tinggi badan (cm) & $155,7(3,7)$ & $157,2(4,8)$ & $0,276^{\text {a) }}$ \\
Blokade sensorik & & & \\
Th5 & 8 & 13 & $0,205^{\text {b) }}$ \\
Th6 & 12 & 7 & \\
$\begin{array}{l}\text { Onset (menit) } \\
\text { Waktu penyuntikan sampai } \\
\text { bayi lahir (menit) }\end{array}$ & $3,0(0,6)$ & $3,2(0,7)$ & $0,328^{\text {a) }}$ \\
\hline
\end{tabular}

Keterangan: nilai p dihitung berdasarkan uji : a) t tidak berpasangan (independen), b) Chi-kuadrat, perbedaan bermakna jika $\mathrm{p}<0,05$ 


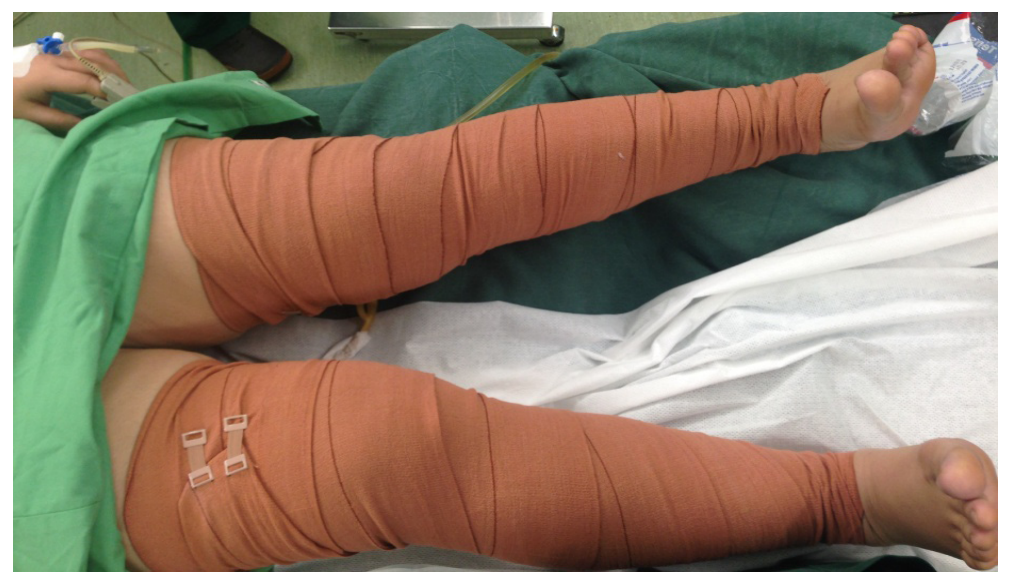

Gambar 1 Penggunaan Leg Wrapping

Keterangan: Dokumentasi Yunita Susanto Putri

tidak berdistribusi normal menggunakan Uji Mann-Whitney dengan tingkat kepercayaan $95 \%(\alpha=5 \%)$. Data kategorik digunakan uji chikuadrat dan nilai $\mathrm{p}<0,05$ dianggap bermakna secara statistika.

\section{Hasil}

Penelitian ini dilakukan terhadap 40 pasien yang dibagi menjadi dua kelompok, tiap-tiap kelompok terdiri atas 20 pasien. Hasil analisis statistika memakai uji-t dan Uji Mann Whitney menunjukkan bahwa karakteristik usia, tinggi badan, tinggi blokade sensorik, onset, dan waktu penyuntikan sampai bayi lahir pada kedua kelompok perlakuan tidak berbeda bermakna ( $p>0,05$; Tabel 1$)$.

Kejadian hipotensi pada kelompok tanpa wrapping terjadi pada hampir semua pasien, sedangkan pada kelompok wrapping tidak terjadi hipotensi pada semua pasien sehingga perbedaan kejadian hipotensi kedua kelompok dinyatakan sangat bermakna $(\mathrm{p}<0,01$; Tabel 2). TDS kelompok wrapping cenderung lebih tinggi dan stabil dibanding dengan kelompok tanpa wrapping (Gambar 2).

Penanganan hipotensi yang terjadi adalah dengan pemberian efedrin sebanyak $5 \mathrm{mg}$ intravena sampai TDS kembali normal (di atas $90 \mathrm{mmHg}$ ). Pada penelitian ini efedrin hanya diberikan pada kelompok tanpa wrapping yang rata-rata setiap pasien membutuhkan 5-10 mg efedrin intravena, sedangkan pada kelompok wrapping tidak diberikan efedrin sama sekali sehingga didapatkan perbedaan sangat bermakna $(p<0,01)$.

Temuan lain pada penelitian ini yaitu efek samping anestesi spinal seperti menggigil dan mual muntah. Bradikardia tidak ditemukan dalam hasil penelitian ini, namun didapatkan

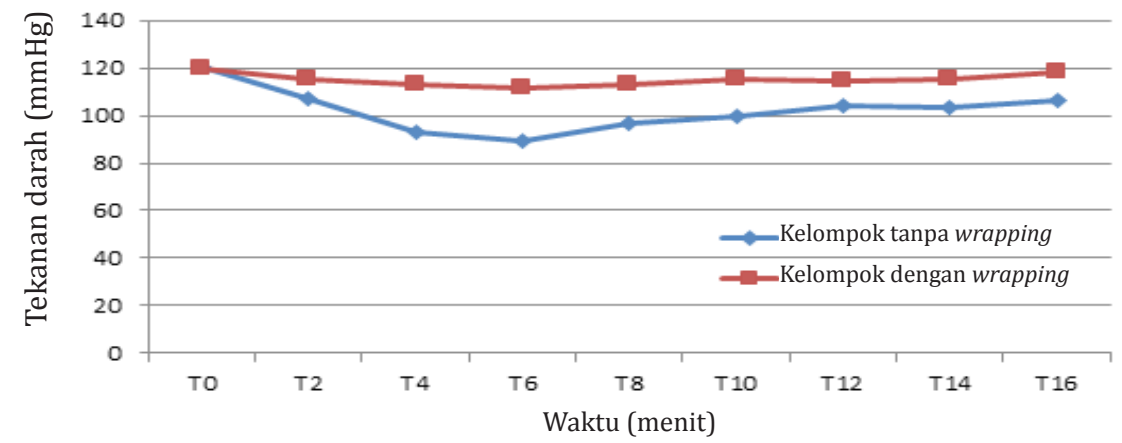

Gambar 2 Perbandingan Tekanan Darah Sistol pada Kedua Kelompok 
Tabel 2 Perbandingan Kejadian Hipotensi pada Kedua Kelompok

\begin{tabular}{lccc}
\hline Kejadian Hipotensi & $\begin{array}{c}\text { Kelompok } \\
\text { Tanpa Wrapping } \\
(\mathbf{n = 2 0})\end{array}$ & $\begin{array}{c}\text { Kelompok Wrapping } \\
(\mathbf{n = 2 0})\end{array}$ & Nilai $\mathbf{p}$ \\
\hline Ya & 19 & 0 & 0,000 \\
Tidak & 1 & 20 & \\
\hline
\end{tabular}

Keterangan: nilai $p$ dihitung berdasarkan uji chi-square, perbedaan sangat bermakna jika $p<0,01$

Tabel 3 Perbandingan Efek Samping pada Kedua Kelompok

\begin{tabular}{lccc}
\hline \multicolumn{1}{c}{ Efek Samping } & $\begin{array}{c}\text { Kelompok Tanpa Wrapping } \\
(\mathbf{n = 2 0 )}\end{array}$ & $\begin{array}{c}\text { Kelompok Wrapping } \\
(\mathbf{n = 2 0 )}\end{array}$ & Nilai p \\
\hline Bradikardia & 0 & 0 & 1,000 \\
Menggigil & 6 & 5 & 1,000 \\
Mual muntah & 18 & 0 & 0,000 \\
\hline
\end{tabular}

Keterangan: nilai p dihitung berdasarkan uji Chi-kuadrat, perbedaan bermakna jika $p<0,05$

kejadian menggigil pada kedua kelompok dengan perbedaan tidak bermakna $(p>0,05)$. Tidak ditemukan kejadian mual dan muntah pada kelompok wrapping, namun terdapat 18 orang pasien pada kelompok tanpa wrapping yang mengalami mual muntah (Tabel 3).

\section{Pembahasan}

Berdasarkan data karakteristik umum pada Tabel 1 dapat dilihat perbandingan usia, tinggi badan, ketinggian blokade sensorik, onset, dan waktu penyuntikan sampai bayi lahir dari kedua kelompok homogen sehingga penelitian ini dapat dianalisis lebih lanjut.

Penelitian ini menunjukkan bahwa leg wrapping yang dilakukan sebelum anestesi spinal pada seksio sesarea dapat menurunkan insidensi hipotensi dengan cara mencegah pengumpulan darah dari sentral ke tungkai bawah. ${ }^{1,7-9}$ Hal tersebut sesuai dengan hasil penelitian sebelumnya, yaitu pada kelompok tanpa wrapping, sebanyak 19 dari 20 pasien mengalami hipotensi (Tabel 2), ditandai penurunan tekanan darah sistol lebih dari $20 \%$ dari tekanan darah awal. Perbandingan angka kejadian hipotensi ini menunjukkan hasil yang sangat bermakna secara statistik.

Hipotensi yang terjadi selama anestesi spinal merupakan akibat dari blokade simpatis, vasodilatasi perifer, serta penurunan tonus vena dan arteri yang menurunkan systemic vascular resistance (SVR) serta redistribusi volume darah sentral $500 \mathrm{~mL}$ sampai 600 $\mathrm{mL}$ ke kompartemen perifer. Pengumpulan darah di tungkai bawah dan abdomen yang menyebabkan hipotensi ini dapat dikurangi dengan intervensi leg wrapping. Leg wrapping dapat mencegah akumulasi darah di tungkai bawah karena ekspansi vena dan darah dapat kembali ke sirkulasi sistemik. ${ }^{1,10,11}$

Penelitian sebelumnya yang dilakukan di India didapatkan hasil $90 \%$ pasien dengan leg wrapping tidak mengalami hipotensi dan sebanyak 43,33\% pasien tanpa leg wrapping yang mengalami hipotensi, sedangkan pada penelitian ini diperoleh hasil bahwa semua pasien dengan leg wrapping tidak mengalami hipotensi, sedangkan 19 dari 20 pasien tanpa leg wrapping mengalami hipotensi. Perbedaan hasil ini dapat disebabkan oleh perbedaan dosis anestesi lokal yang digunakan di tiaptiap tempat. Di India digunakan dosis 12,5 mg bupivakain $0,5 \%$, sedangkan pada penelitian ini digunakan dosis $10 \mathrm{mg}$ bupivakain 0,5\%. Selain itu, terdapat juga perbedaan definisi hipotensi, pada penelitian di India hipotensi terjadi bila tekanan darah sistol $\leq 90 \mathrm{mmHg}$, 
sedangkan pada penelitian ini hipotensi terjadi bila terdapat penurunan $\geq 20 \%$ tekanan darah sistol dari data awal. Pemilihan kriteria hipotensi yang berbeda ini disebabkan oleh perbedaan tekanan darah sistol awal pada tiaptiap pasien sehingga penelitian ini memakai kriteria hipotensi dengan penurunan $\geq 20 \%$ tekanan darah sistol awal.

Gambar 2 memperlihatkan tekanan darah sistol pada pasien kelompok tanpa wrapping cenderung lebih rendah dibandingkan dengan kelompokwrapping. Haltersebutsesuaidengan penelitian yang pernah dilakukan sebelumnya di India dan Afrika Selatan bahwa tekanan darah sistol pasien dengan leg wrapping lebih tinggi dan stabil bila dibanding dengan tanpa leg wrapping. Hasilnya menunjukkan bahwa penggunaan leg wrapping sebelum anestesi spinal dapat mencegah hipotensi selama anestesi spinal pada pasien yang menjalani seksio sesarea. Hal ini dapat terjadi karena leg wrapping diduga dapat meningkatkan volume darah sentral sehingga dapat mencegah terjadi hipotensi. Teknik ini dapat mencegah hipotensi relatif akibat blokade simpatis yang terjadi berkaitan dengan anestesi spinal dan kompresi aorto kaval tekanan uterus. ${ }^{1,9}$

Setiap kejadian hipotensi ditangani dengan pemberian efedrin $5 \mathrm{mg}$ intravena hingga tekanan darah sistol kembali normal (di atas $90 \mathrm{mmHg}$ ). Pada kelompok wrapping tidak didapatkan pasien yang mengalami hipotensi ataupun mendapatkan terapi efedrin. Efedrin merupakan obat pilihan dalam menangani hipotensi karena menghasilkan vasokontriksi pembuluh darah uterus yang poten sehingga dapat meningkatkan aliran darah uterus tanpa meningkatkan uterine vascular resistance. ${ }^{11}$

Efek samping lain anestesi spinal adalah bradikardia, mual muntah, dan menggigil. Pada penelitian ini tidak didapatkan efek samping bradikardia pada kedua kelompok. Pada kelompok tanpa wrapping didapatkan 6 dari 20 pasien yang mengalami menggigil, sedangkan kelompok wrapping didapatkan 5 dari 20 pasien mengalami menggigil. Hasil ini menunjukkan tidak ada perbedaan bermakna antara kedua kelompok, namun hasilnya belum dapat dinyatakan akurat dikarenakan keterbatasan pada jumlah sampel. Penelitian mengenai efek samping ini sebaiknya diteliti lebih lanjut dengan jumlah sampel yang lebih banyak.

Efek samping mual muntah terjadi pada 18 dari 20 pasien kelompok tanpa wrapping dan tidak terdapat pasien kelompok wrapping yang mengalami mual muntah sehingga secara statistika penelitian ini menunjukkan hasil yang berbeda bermakna $(\mathrm{p}<0,01)$. Pada tahun 2012 telah dilakukan penelitian di Iran mengenai mual muntah pada pasien seksio sesarea dalam anestesi spinal dan didapatkan $73,6 \%$ pasien yang mengalami mual muntah. Penyebab mual muntah tersebut diduga adalah penurunan aliran darah ke otak akibat hipotensi sehingga tindakan untuk mengatasi kejadian mual muntah pascaanestesi spinal adalah dengan mengatasi hipotensi. Kejadian mual muntah pada parturien juga dipengaruhi oleh perubahan hormon progesteron pada wanita hamil, usia, dan juga riwayat emesis sebelumnya. ${ }^{12,13}$

\section{Simpulan}

Penggunaan leg wrapping sebelum dilakukan anestesi spinal pada pasien yang menjalani operasi seksio sesarea menurunkan angka kejadian hipotensi. Sebagai saran praktis pada pasien hamil yang terbiasa menggunakan stokingkompresi dapattetap menggunakannya selama seksio sesarea karena penggunaan tersebut dapat menurunkan kejadian hipotensi selama anestesi spinal pada seksio sesarea.

\section{Daftar Pustaka}

1. Singh K, Payal YS, Sharma JP, Nautiyal R. Evaluation of hemodynamic changes after leg wrapping in elective cesarean section under spinal anesthesia. J Obstet Anesth Crit Care. 2014;4:23-8.

2. Fröhlich MA. Obstetric anesthesia. Dalam: Morgan GE, Mikhail MS, Murray MJ, penyunting. Clinical anesthesiology. Edisi ke-5. Amerika Serikat: McGraw-Hill; 2013. hlm. 855-7.

3. Chestnut DH, Polley LS, Tsen LC, Wong 
CA, penyunting. Chestnut's obstetric anesthesia principles and practice. Edisi ke-4. Philadephia: Mosby Elsevier; 2009.

4. Baraka A. Can we minimize hypotension following spinal anesthesia for cesarean section. MEJ Anesth. 2010;20(5):619-20.

5. Kee WDN. Prevention of maternal hypotension after regional anesthesia for caesarean section. Curr Opin Anesthesiol. 2010;23:304-9.

6. Arendt K, Muehlschlegel JD, Tsen LC. Cardiovascular alterations in the parturient undergoing cesarean delivery with neuraxial anesthesia. Expert Rev Obstet Gynecol. 2012;7(1):59-75.

7. Kaya S, Karaman H, Erdogan H, Akyilmaz A, Turnaoglu S. Combined use of low dose bupivacaine, colloid preload and wrapping of the legs for preventing hypotension in spinal anesthesia for caesarean section. Intern Med Res. 2007;35:615-25.

8. Jabalameli M, Soltani HA, Hasemi J, Behdad S, Soleimani B. A randomized comparative trial of combinational methods for preventing post-spinal hypotension at elective cesarean delivery. J Res Med Sci. 2011;16(9):1129-38.

9. Khedr NF. Preventive measures to reduce post spinal anesthesia hypotension forelective cesarean delivery. J Am Sci. 2011;7(2):634-40.

10. Bishop DG. Predicting spinal hypotension during caesarean section. South Afr J Anesth Analg. 2014;20(4):170-3.

11. Mercier FJ, Auge M, Hoffmann C, Fischer C, Le Gouez A. Maternal hypotension during spinal anesthesia for caesarean delivery. Minerva Anestesiol. 2012:79(1):62-73.

12. Scott J, Flood P. Anesthesia for caesarean section. Dalam: Hines RL, penyunting. Obstetric and gynecologic anesthesia. Edisi ke-1. Philadephia: Elsevier Mosby; 2006. hlm. 57-64.

13. Jabameli M, Honarmand A, Safavi M, Chitsaz M. Treatment postoperative nausea and vomiting after spinal anesthesia for cesarean delivery: a randomized, doubleblinded comparison of midazolam, ondansetron, and a combination. Adv Biomed Res. 2012;1:2-7. 